\title{
Discussion on Human Resource Management Reform of Higher Vocational Institutes in Guizhou Province
}

\author{
Qinyi Liu \\ Guizhou Vocational Technology College of Electronics and Information, Kaili, 556000, Chna
}

Keywords: Higher vocational institutes, Human resource management of faculty, Current situation

\begin{abstract}
As a comparatively underdeveloped province, Guizhou is mainly deficient in gross of talents, structure of personnel and quality of brains. Besides, no matter from structure nor from quality, the present teaching staffs of higher vocational institutes within Guizhou province, are far from meeting the current development needs for cultivating practical, inter-disciplinary and technical personnel in higher vocational education. Thus, based on the analysis of existing situation in Guizhou's technical colleges, this paper also discusses about the disparity between higher vocational colleges and higher educational institutions as well as the comparison between traditional technical colleges and corresponding transitional counterparts in the aspect of human resource management. Then it raises several questions mainly including faculty influx, teacher training, performance assessment and salary administration. In addition, the paper also proposes a series of suggested policies accordingly aimed on the previously mentioned issues, such as optimizing faculty structure, diversifying talent channel, variegating teacher training and stimulating performance assessment with great efficiency. Despite some negative effects on the later execution, out of the restrictions in national and local policy, overall social environment and college's own factor, which leads to some inadequate results of those suggestions, I myself will continue to work on this task with further exploration and deep analysis in order to find out a better solution plan.
\end{abstract}

\section{Introduction}

As an inland province a bit close to coastal ports and Yangtze River, Guizhou is greatly restricted by its geographical location which makes its economy stay semi-closed for a long period, low productivity and comparatively laggard economy and culture. Considering the absence of innate advantage in geography, the original reform and development plan confirms to develop Guizhou in subsequent period. Thus, in recent years, Guizhou province as a whole has been relatively backward accompanied by a brain strain, which also largely impedes the sustainable development of Guizhou. The internal training mode is a possible solution to Guihzou's current problems. However, it may also present a severe situation for all the higher vocational institutes.

\section{Expanded Running Size of Vocational Institutes with Low Overall Quality}

Most of the higher vocational institutes in Guizhou are now in a groping stage, so they still basically follow the previous management system and administration mode without updated adjustment for new times. Meanwhile, during the process of talent cultivation, they are still confined by a work-oriented educational philosophy which merely aims to develop future technical worker rather than an education-oriented concept. In this way, they ignore the great difference between a student from higher vocational institute and the one from technical secondary school. Additionally, no matter for the executive leadership or the teaching faculty, such an old team still follows the previous education system and its mode. Therefore, it makes the present higher vocational institutes far less qualified as a whole.

\section{The Dilemma in Overall Construction of High Vocational Teaching Resources}

By far, about 70\% teaching faculties in Guizhou's higher vocational and academic institutes are classified as "university-college" mode. In other words, most of them are employed as teachers of 
vocational colleges as soon as they graduate from universities. Therefore, short of the contact with society, those teachers are only able to impart more theoretical knowledge they acquired from universities to the students, and such kind of instruction is far from enough for higher vocational institutes to cultivate a group of skilled personnel. Therefore, based on the present problems of higher vocational institutes in Guizhou, the author of this paper accordingly conducts a field research and finally summarizes a series of points shown as below.

\section{Faculty Introduction}

In view of Guizhou's geographical disadvantage and economic underdevelopment, it is particularly difficult for all the higher vocational institutes in this area to attract great professional elites from other regions. During the interview, the head of personnel from Kerry College pointed out "because of our transformation from a previous academy to a present university, we now raise our standards in faculty recruitment which requires at least a master degree. However, in view of the practical experience of recent two years, it suggests that about $40 \%$ postgraduates cannot well finish their teaching tasks, which invisibly results in an extra sum of expense to employ a group of experienced teachers off the campus who are just unqualified in educational requirement to complete the rest of tasks.

For higher vocational institutes, they can just examine candidates simply from their academic diplomas and trial lectures during the process of recruitment. There is no way to work out an efficient assessment system to examine their comprehensive ability and competence. If there is anything wrong with candidate's performance during probation period, the institute could postpone his time to become a full member; while if unfortunately, such a problem is found after probation period, and then this employee cannot be discharged unless any severe disciplinary offence is made, which hence poses a great pressure on institute's human resources.

\section{Teacher Training}

Teacher training is usually implemented at the end of each term which is based on the institute's specific requirement to arrange its contents and trainees. There is no existing good system to abide by, and thus the training fails to play effect in trainees'career performance; meanwhile, the feedback of current teacher training is either recorded by a relevant division in the department or by a personnel office. After the training, teachers receive nothing except for the feedback on their summary reports from training party. Therefore, it reflects a severe absence of a scientific, efficient and systematic system in examination, supervision and assessment. On account of such a deficiency in efficient evaluation system, it is hard to tell the exact model of training that is suitable for teachers in higher vocational institutes, and as a result, it makes the training a heavy burden losing its original essence.

\section{Performance Assessment}

For higher vocational institutes, the purpose of performance assessment is to make an overall analysis and assessment about teacher's competence, potential and attitude etc. during their instruction by this means. Moreover, according to the evaluation results, it then makes a corresponding guideline and efficient solution for each teacher to further improve his competence. However now, the performance assessment in higher vocational institutes depends mostly on the evaluation to make a performance ranking which is also related to teacher's salary and bonus to some extent, and in this way, it totally departs from the original purpose and fails to play great effect in its managing function, which finally becomes a holly performance assessment. Besides, the performance assessment at present only stays at the examining phase with no available channel for teachers to get their evaluation feedbacks, let alone the counseling for their performance assessment and the communication during the execution period. Consequently, it is insignificant to continue such an assessment for those teachers who haven't reach excellence since they cannot receive their evaluation in time and accordingly know about their exact need-to-be-improved aspects. 


\section{Salary management}

Nowadays, for most of higher vocational institutes within Guizhou, they still adopt an old calculative basis which has been used over ten years to calculate faculty's workloads. Ignoring the present economic development as well as the recent currency inflation, this basis still adheres to the original standard, 20 Yuan per class. On account of low pay, a number of teachers are no longer willing to undertake many teaching tasks. That's why some colleges make a mandatory rule that a certain amount of teaching tasks is allotted to each teacher as a part of the performance assessment, in other words, any failure in such prescribed teaching tasks will result in a negative impact on both evaluation result and regular post allowance. In addition, some colleges ignore the disparity among teachers'competences and adopt egalitarianism in calculative basis, leading to an inactive performance of teachers at class couple with no further improvement of their teaching quality.

In view of the current problems existing in Guizhou's vocational colleges, it could apparently tell that a great reform in human resource management is around the corner. In this reform, the key points mostly lie in the optimizing faculty structure, diversifying talent channel, variegating teacher training and stimulating performance assessment with great efficiency. Thus, based on the issues above, the author of this paper proposes a series of suggestions shown as below:

Mandatory Rules on the Practical Working Experience in Society of Newly-employed Faculty

For all the employed teaching faculties, higher vocational institutes should not only concentrate on their academic degrees but also very importantly, their practical competences, especially according to each college's own characteristics and the successful running experience from other foreign vocational colleges, to build a "bi-teacher" team construction. Thus, those "bi-teachers" possess great expertise not only in theoretical knowledge but also in practical field, and then it also benefits the actual teaching process from efficiently combining theory and practice. Also, this can avoid the possibility that once students graduate from higher vocational institutes and come to work, they feel particularly overwhelmed and innocent about everything. During the brain influx, for those teachers unqualified in social working experience, colleges can act according to the different actuality of each major and later make an active contact with relevant companies for them after recruitment. Then, based on their actual working period and performance evaluation in firms, employees who have reached good level or above are then able to officially become full-time teachers.

Privileged Policy and Relevant Assistance from Local Governments at Various Levels for Higher Vocational Institutes Based on Their Own Actuality

During the introduction of talents, local governments at all levels ought to actively exploit their advantages to the full to assist higher vocational institutes with corresponding privileged policies according to their different situations and then truly realize its trinity in the construction of "government-institutes-enterprises". To achieve such a plan, government should complete several targets as below: 1. distribute certain powers to all institutes and allow them to scheme characteristic policies and plans compatible with their own reality. Thus, it eases the administrative burden of government and at the same time, better meets the specific need of each institute and avoids an autocratic style of leadership. 2. Keep pace with the overall development in society and make a correct prediction of future developing trend as to revise relevant policies in advance.

Establishing a People-oriented Training System

Training itself is not an individual event but a systematic and complicated program, or rather, a bidirectional behavior system. Hence, the training content should not be made merely by institutes but more by the joint effort between colleges and teachers to scheme a wide range of training contents and modes in view of teachers'different needs, their own practical situations and the future developing positioning of college. Such a plan puts great emphasis on the pre-service training of new teachers, which enables them to grasp basic teaching skills within the shortest time as well as on the skill training of inexperienced teachers, which allows them to enrich themselves with practical experience in training base or relevant companies. Last but not least, for key teachers and "bi-teachers", this plan also benefits them from offering visiting scholar opportunities, foreign study programs and further education projects, as to improve their professional abilities and vocational levels. 
Changing Concepts and Creating a Good Environment for Performance Assessment

In order to alter the current situation, the first step is to make some change in the administrative concept of leadership team and executive examiner about performance assessment. Thus, to set up a correct idea about performance assessment among leaders, it firstly suggests to hold a training seminar about modern management for executive leadership, and then after such a long period of idea input, it comes to a close combination between faculty's assessment results and college's future development, which requires a series of different assessment means when evaluating teachers from various levels. In detail, it means to strengthen the assessment of teaching skill, professional quality and social practice of those newly employed faculty; while as for the junior teachers experienced in social practice, the emphasis lies on their teaching skills, professional competence and participation in theoretical teaching reform; moreover, for those "bi-teachers" with senior titles, the key point of assessment shifts to their involvements in education reform, curriculum revolution and scientific research; at the end, the evaluation of experienced teachers with certain scientific competence and sub-senior titles or above, depends mainly on their training of new teachers, teaching and scientific research achievement, etc.

Perfect the Feedback System of Performance Assessment

For the concrete implementation of performance assessment, the evaluator is required to regularly communicate with teachers to find out their problems and difficulties in the practical process of completing assessing targets and to jointly work out corresponding solutions rather than directly checks the final results after the evaluation process. For some problems beyond evaluator's ability, teachers can submit their report to superiors and ask for further assistance. After the year-end assessment, the evaluator should seriously summarize and analyze the assessment results and holds a talk with each teacher respectively, whose purpose is to approve their achievements rather than to criticize the disadvantages. For their shortage, the two will make a joint effort to find the original factor, to make an improvement plan and to scheme an action project for the next stage of assessment.

\section{Conclusion}

This paper firstly makes an analysis about Guizhou in the aspects of its economy and geography, and then it finds out a series of common problems existing in the human resource management of Guizhou's higher vocational institutes through a further study of present situation of those colleges, a variance analysis in human resource management between higher vocational institutes and higher educational universities and the study of such management in different kinds vocational colleges. Besides, the paper then further explores those issues and finally proposes several concrete solutions and suggestions for Guizhou's higher vocational institutes with the consideration of local situations that are optimizing faculty structure, diversifying talent channel, variegating teacher training and stimulating performance assessment with great efficiency. However, those solutions and suggestions cannot be implemented by only one party. A joint effort is required among institute authority, department leadership, relevant administrative division and teaching faculty. Thus, human resource management apparently is not a unidirectional activity, but a multidirectional and integrated system. Hence, for the current developing needs, those solutions and suggestions should concentrate more on the people-oriented concept during the management process and introduce several important human resource management theories into the faculty training and incent assessment system.

\section{Reference}

[1] Raymond A.Noe. Human Resource Management Gaining a Competitive Advantage. Beijing: Renmin University of China Press, 2001.

[2] Yu Wenzhao. Modern Incentive Theory and Application. Dalian: Dongbei University of Finance and Economics Press, 2014.

[3] Wang Yun, Sun Jing. Human Resource Managemen. Beijing: Tsinghua University Press, 2008. 